\title{
CORRELATION STUDIES FOR THE IN-PLANE ANALYSIS OF MASONRY WALLS BASED ON MACROSCOPIC FE MODELS WITH DAMAGE
}

\section{MARIACARLA NOCERA ${ }^{1 *}$, LUIS C. SILVA ${ }^{2}$, DANIELA ADDESSI ${ }^{1}$ AND PAULO B. LOURENÇO ${ }^{3}$}

\author{
${ }^{1}$ Department of Structural and Geotechnical Engineering \\ University of Rome Sapienza \\ Via Eudossiana 18, 00184 Rome, Italy \\ e-mail : (mariacarla.nocera, daniela.addessi)@uniroma1.it \\ ${ }^{2}$ Institute for Sustainability and Innovation in Structural Engineering - ISISE \\ Universidade do Minho \\ 4800-058 Guimarães, Portugal \\ e-mail : luiscsilva@civil.uminho.pt,web page: www.hms.civil.uminho.pt \\ ${ }^{3}$ Department of Civil Engineering, ISISE, University of Minho \\ Campus de Azurém 4800-058 \\ Guimarães, Portugal \\ e-mail : pbl@civil.uminho.pt
}

Keywords: Masonry structures, Macromechanical finite element, Damage, Crack, Plasticity.

\begin{abstract}
This study explores the use of macro-modelling techniques based on smeared crack and damage-plastic constitutive laws for the cyclic in-plane analysis of masonry panels. The numerical investigation is focused on two material macromechanical models, known as Total Strain Cracking and Crack and Plasticity models. These show some limitations when analysing the behaviour of masonry structures subjected to in-plane cyclic loading. A modified version of the Drucker-Prager model including cohesive softening is introduced to overcome these shortcomings.

A suite of numerical simulations is performed referring to an experimental campaign on two masonry (squat and slender) panels. A comparison of distinctive features of flexural and shear response of masonry panels is addressed. The results derived from the two FE macro-models are compared with the experimental outcomes, highlighting the effects of geometry, stiffness degradation, and post-peak energy dissipation. Furthermore, a comparison with another macromechanical model is performed.
\end{abstract}

\section{INTRODUCTION}

Masonry buildings are a relevant part of the existing civil, architectural and cultural heritage. The preservation of their structural integrity is a very challenging task, requiring the development of accurate and efficient procedures to assess their safety and stability. 
Unreinforced masonry structures typically show a high seismic vulnerability and require repairing and strengthening interventions to reduce their collapse risk [1]. An accurate evaluation of the unreinforced structure response is a fundamental step, given the complexity and heterogeneity of masonry material, to design possible efficient interventions. The main aim is to investigate the onset and evolution paths of the damaging mechanisms that can lead to the structural collapse under seismic actions. Several studies were conducted to characterize the different damage mechanisms, which can be caused from various external actions, and study how to provide the safety of these constructions [2]. Analytical and numerical procedures based on different modelling approaches exist in the literature [3]. The main available strategies for masonry structures can be broadly classified as follows: limit analysis, where limit plasticity theorems are applied to evaluate the static response of the structures, macroelement models, where the constructions are idealized in structural components adopting nonlinear constitutive laws, finite element modelling (FEM), where the structures are discretized with different detail scales, and discrete element method, where the buildings are described as an assemblage of distinct blocks interacting along the boundaries. A comprehensive and more detailed review can be found in [4].

Limiting the attention to FEM, different approaches can be recognized as micromechanical and macromechanical formulations. The former approach describes masonry in detail, differentiating between block, mortar and interfaces [5]-[7]. The information on the geometry, texture and constituents is accurately described, as well as their constitutive behaviour. In the latter approach, the real heterogeneous masonry material is substituted by an effective homogeneous continu un be introduced [8]-[12 the aim of reproducing Macromechanical finite large to super large problems. The macro damage and/or plasticity model. Damage models are often combined with a plasticity

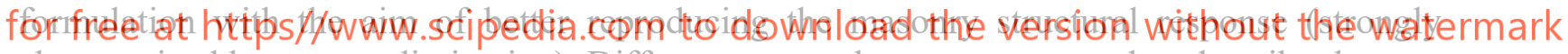
characterized by energy dissipation). Different approaches were proposed to describe damage from a phenomenological point of view. In particular, models based on the classical theory of Continuum Damage Mechanics [14], in which the material is assumed as a continuum medium, or formulated according to Fracture Mechanics theory, in which discrete cracks of finite size are explicitly modelled, can be distinguished.

In 1968, Rashid introduced the smeared crack formulation, that is a counterpart of the discrete crack concept. This considers the medium, where different cracks are present, as a continuum material [15]. The simplicity of the approach captured the attention of the scientific community and most of the FE codes have adopted this approach. In such a context, this paper investigates the use of macromechanical constitutive models to analyse the nonlinear degrading response of masonry structures. In particular, the study focuses on two material constitutive laws belonging to the class of the so-called Smeared Crack Models (SCM), known as Total Strain Cracking and Crack and Plasticity $[15,16]$. The results of the experimental campaign conducted by Anthoine et al. [18] are numerically reproduced and a comparison on distinctive features amid the flexural and shear responses of masonry panels is addressed. Firstly, monotonic tests are performed to validate the mechanical parameters deduced from literature and prove the model's efficiency to reproduce the real damage mechanisms. Then, the cyclic behaviour of the tested 
masonry panels is investigated under in-plane cyclic loading. Some of the limitations of the models are highlighted and, to overcome such restrictions, a modified version of the DruckerPrager model including cohesive softening is proposed. The effects of the geometry, stiffness degradation, and post-peak energy dissipation are investigated. Comparisons between the adopted macro-models and the experimental outcomes are shown in terms of global in-plane cyclic response of the masonry panels; meaning the envelope capacity curve and the crack mechanisms. Furthermore, the results from a continuum damage-plastic model proposed in Gatta et al. [13] is also addressed.

\section{MACROMECHANICAL MODELS FOR MASONRY}

This section describes the macromechanical finite element models adopted to numerically reproduce the structural response of the masonry panels from the selected experimental campaign. A brief description on the constitutive laws is first stated and the differences between the models are highlighted after. Finally, a short comment on the employed regularization technique to overcome the mesh-dependency of the FE solution is also provided.

\subsection{Smeared crack and continuum damage constitutive models}

Two smeared crack models implemented in the FE code DIANA [19] are first described, the so-called Total Strain Cracking and Crack and Plasticity models. A modified version of the latter is also presented to better reproduce some features of the nonlinear response of masonry

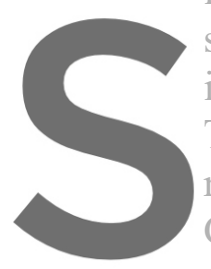
structures. At the end, introduced [13] with the The Total Strain Cracki rotating and fixed multi-directional smeared Crack (TSRC) model is
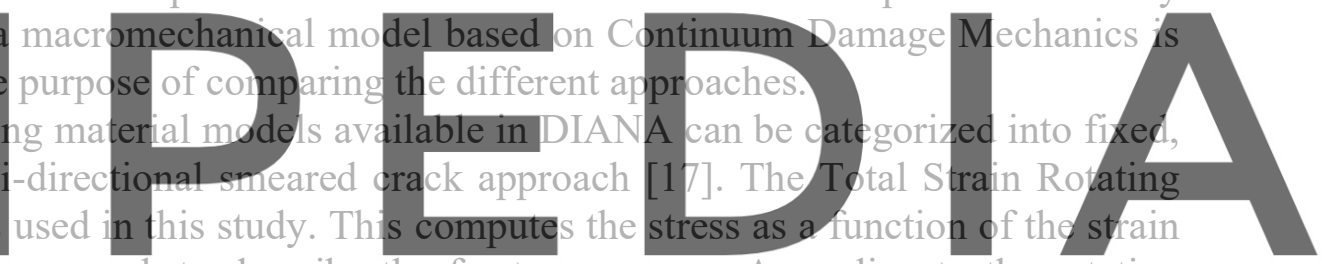

and follows a smeared approach to describe the fracture process. According to the rotating

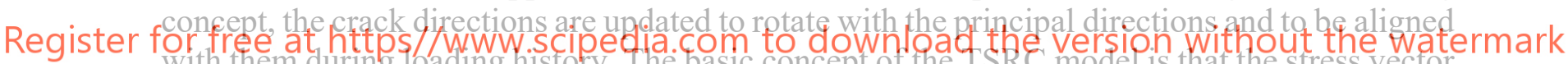
with them during loading history. The basic concept or the ISRe model is that the stress vector

is evaluated according to the intrinsic reference system of the crack, given by the axes parallel and orthogonal to the crack. The smeared fracture process is activated when the maximum principal stress, evaluated at a Gauss point of the FE, exceeds the tensile strength. The shape of the tensile softening diagram controls the cracking phenomenon, being governed by the fracture energy parameter of the material that is given by the area under the stress-strain diagram. Two values are introduced for the fracture energy parameters, i.e. $g_{t}$ and $g_{\mathrm{c}}$ that are associated, respectively, with the tensile and compression behaviours. In this study, an exponential law governs the softening branch in tension and a hardening-softening parabolic law the post-peak response in compression.

The Crack and Plasticity (CP) model is based on the smeared crack approach used to simulate the tensile post-cracking behaviour, whereas the Drucker-Prager plasticity model is adopted to simulate the compressive response. The $\mathrm{CP}$ model can be categorized as a multi-fixed smeared crack model with an elastic-plastic constitutive law in compression. According to the multifixed crack formulation, and differently from the fixed smeared crack model where only one fixed crack can form at each integration point, more than one crack is allowed to form. In the multi-fixed crack model, the first crack is formed perpendicular to the direction of the maximum 
principal stress. After that, another crack is allowed to form if the tensile strength is again violated by the major principal stress and if the angle between the existing crack and direction of the major principal stress exceeds a certain value, i.e. the threshold angle that is usually set to be 30 degrees. As for the TSRC model, the cracking phenomenon is governed by the shape of the tensile softening, defined by the fracture energy $g_{t}$. For this study, post-peak tensile stresses decrease following a linear law.

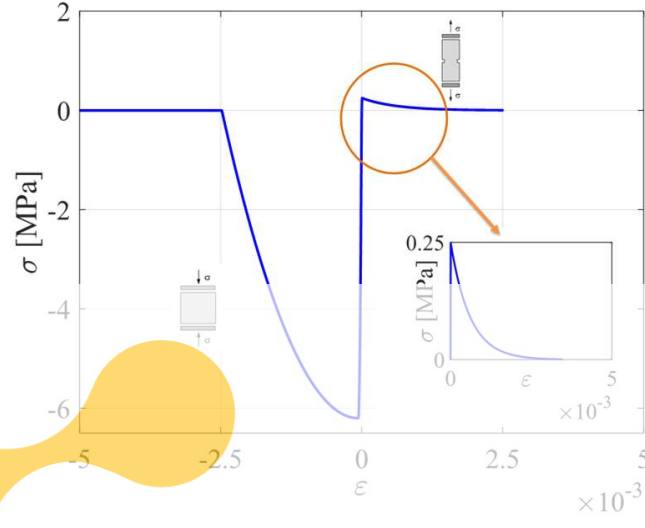

(a)

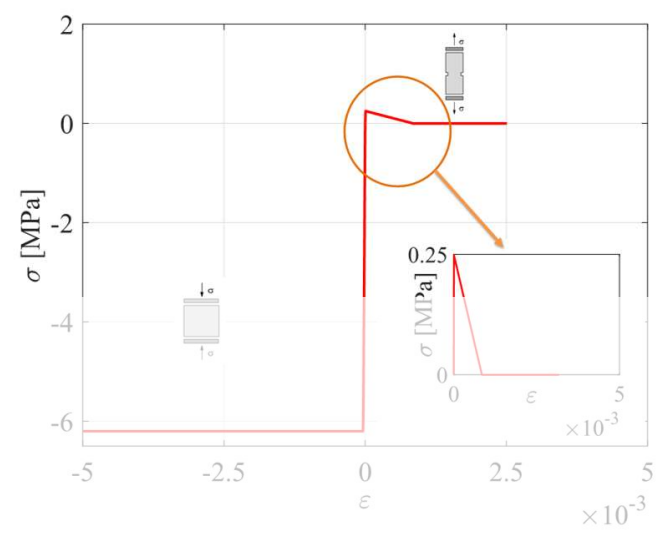

(b)

Figure 1: Masonry stress-strain law: TSRC (a) and CP (b) model.

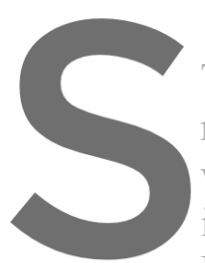

To overcome some reproducing the real it

with the aim of describing the degrading phe is introduced in the Drucker-Prager model, gi

Plasticity model (MCP). The compressive softening law is empirically included in the DruckerPrager model with strain hardening, whereas the tensile response still follows a bi-linear branch.

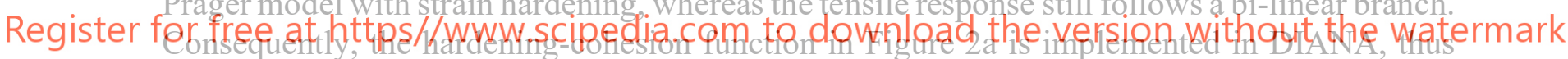
modifying the compressive response of the CP model. Figure $2 \mathrm{~b}$ shows the masonry stressstrain law adopted for the MiCP modei.

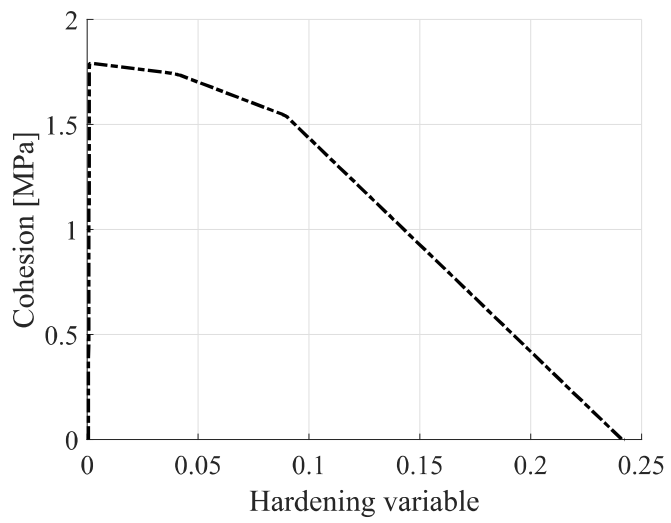

(a)

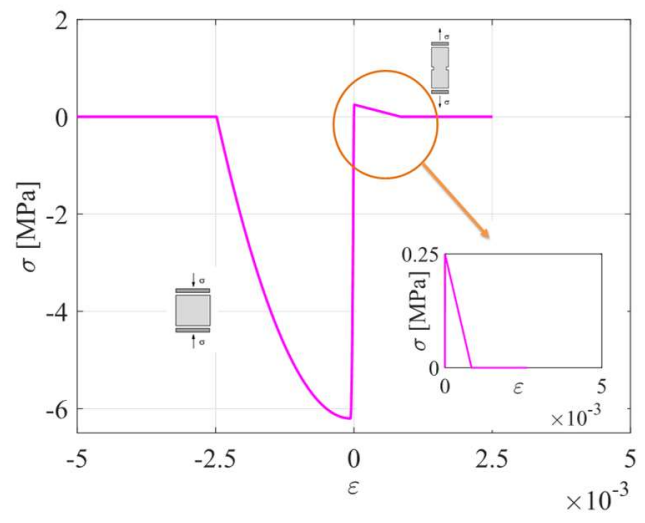

(b)

Figure 2: Cohesion hardening function (a) and masonry stress-strain law for MCP model (b). 
Finally, a macromechanical model based on the classical theory of Continuum Damage Mechanics is investigated [13], here denoted as CDP (continuum damage-plastic) model. The stress-strain constitutive relationship is based on a damage-plastic model, coupling an isotropic two-variable damage model and the Von Mises plasticity formulation with isotropic and kinematic hardening. This is based on the introduction of two different damage variables, distinguished for prevailing tensile and compressive states, to reproduce the unilateral phenomenon, that is the stiffness recovery due to the cracks re-closure when moving from tension to compression.

\subsection{Mesh-dependency and regularization issues}

Different techniques can be adopted to overcome the mesh-dependency of the FE solution, when constitutive laws with strain-softening are adopted. For the smeared crack models presented above, TSRC and CP, a fracture energy regularization is used [20] in order to get mesh independent solutions. This relies on the assumption that dissipation within the single element has to be independent from the element size. To this end, the constitutive law is properly modified such that the energy dissipated in the FE is equal to the assigned value $G_{i}$ with $i=t, c$. For each element, a characteristic length $h^{e}$ is defined, which depends on the size, shape and interpolation function of the used finite element. Both the mentioned models, that is TSRC and CP, make use of the Rots' element based method [15]. The specific fracture energies $g_{i}$, defined as per Eq.(1), is then scaled so that it results $g_{i} h^{e}=G_{i}$ for each element.
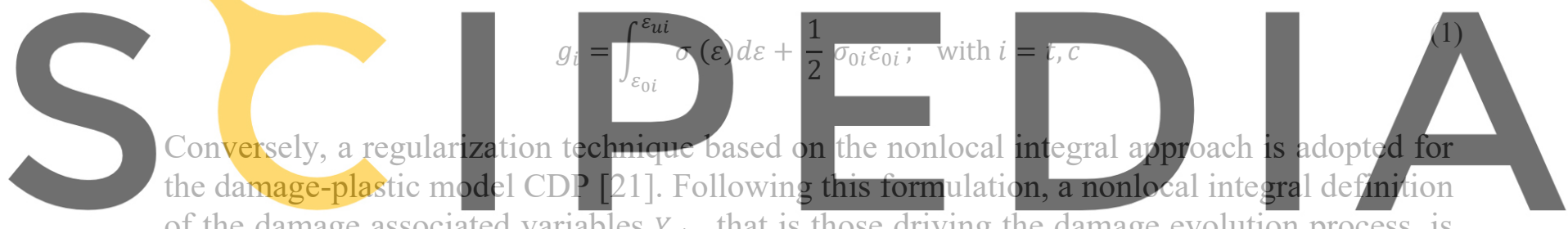

of the damage associated variables $Y_{t / c}$, that is those driving the damage evolution process, is

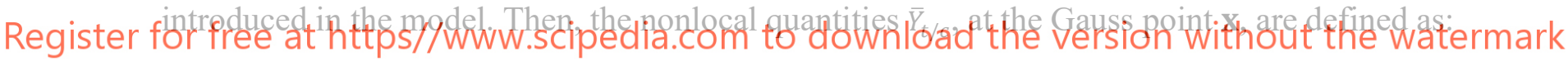

$$
\bar{Y}_{t / c}(x)=\frac{1}{\int_{A} \psi(\boldsymbol{x}, \boldsymbol{s}) d A(\boldsymbol{s})} \int_{A} Y_{t / c}(s) \psi(x, s) d A(s)
$$

in which $Y_{t / c}$ is a local variable at the generic point $\mathbf{s}$ located in a proper defined neighbourhood of point $\mathbf{x}$. The classical Gaussian distribution is assumed as weighting function, with $1_{c}$ denoting the nonlocal radius of the neighbourhood related to the material internal characteristic length.

\section{NUMERICAL APPLICATIONS}

The experimental campaign conducted by Anthoine et. al [18] is here considered (Figure 3a). Two solid clay panels, characterized by different height/width ratio and assuming identical boundary conditions, are investigated. The bottom side of the walls is completely restrained, while the top side is prevented to rotate. The panels are firstly subjected to a vertical force equal to $150 \mathrm{kN}$, kept constant during the test, and then a cyclic horizontal displacement history is applied on a steel beam rigidly connected to the top of the walls. The lateral displacement is imposed quasi-statically and characterized by a cyclically increasing amplitude. Two or three 
cycles are performed for each amplitude. The geometry of the panels is shown in Figure $3 \mathrm{~b}$ and $3 \mathrm{c}$ with the thickness equal to $250 \mathrm{~mm}$.

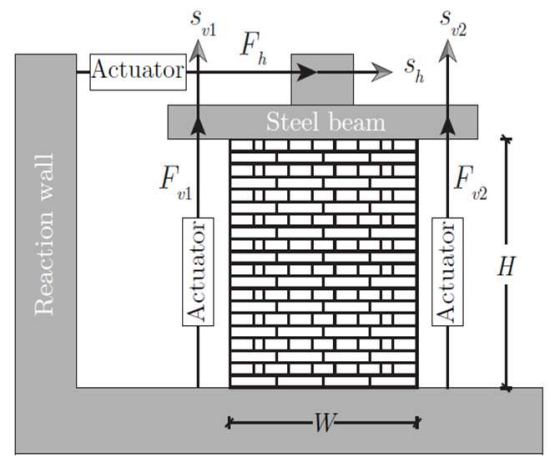

(a)

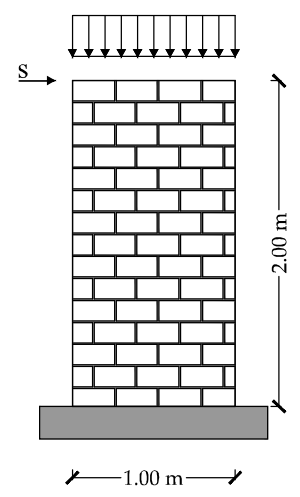

(b)

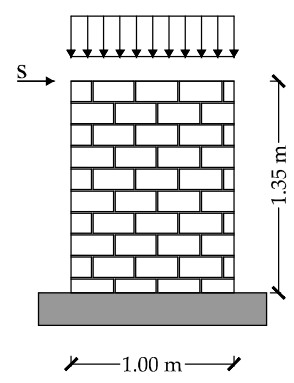

(c)

Figure 3: Experimental campaign selected: (a) setup [18], and geometry of the (b) high panel and (c) low panel.

The experimental response of these panels is compared with the numerical prediction of the macromechanical models described before. A plane stress formulation with a 2D four-point quadrilateral FEs and within a $2 \times 2$ Gauss integration rule is adopted. A mesh made of 10x20 FEs is used for the high panel, while 10x14 FEs are adopted for the low panel. The mechanical parameters used in the

Young's modulus, 1

values, respectively,

chosen according to

mechanical parameters
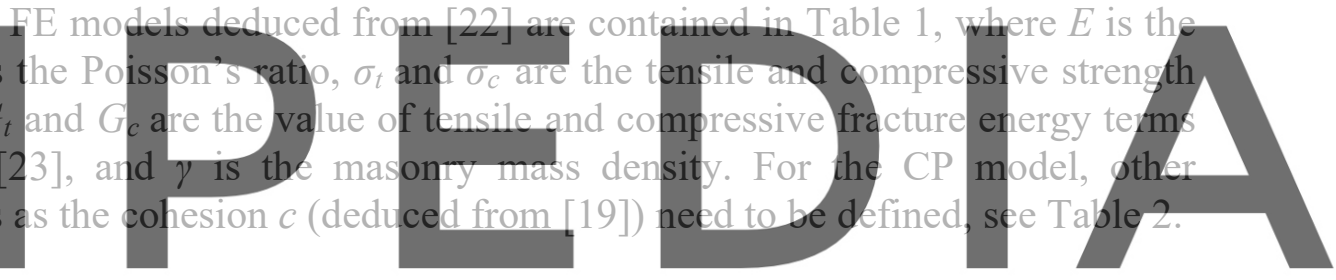

Table 1: Mechanical parametes adopted for the TSRC and CP models.

Register for free at https//WWW.scipedia.com to download the version without the watermark

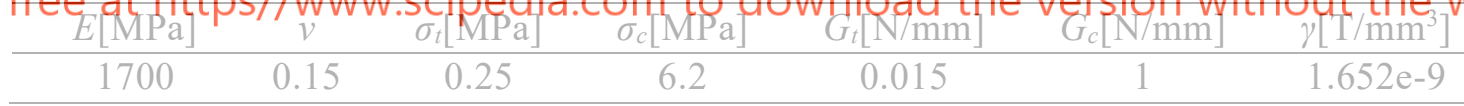

Table 2: Mechanical parametes adopted for the CP model.

\begin{tabular}{ccc}
\hline$c[\mathrm{MPa}]$ & Friction angle [rad] & Dilatancy angle [rad] \\
\hline 1.7898 & 0.5236 & 0 \\
\hline
\end{tabular}

\subsection{Monotonic loading}

Following the experimental loading history, a vertical force equal to $150 \mathrm{kN}$ is applied and kept constant during the test. A monotonic horizontal displacement history is imposed on the top of the walls. The results are monitored in terms of global in-plane response curve, meaning the envelope capacity curve, by depicting the total base shear versus the horizontal applied displacement. Figure 4 shows the comparison between the numerically obtained curves (red dashed curves and blue dashed-point curves) and the envelopes (black star symbols) corresponding to the cyclic experimental response for the high (Figure 4a) and low (Figure 4b) panels. Although some differences emerge between the two models, the numerical results are 
in quite good agreement with the experimental ones. The TSRC model (blue dashed-point curves) gives a smoother nonlinear response, whereas the CP (red dashed curves) shows sudden drops due to crack's formation. Moreover, in the case of the squat (low) panel, the TSRC also shows a sudden brittle strength loss that is not clear for the CP model.
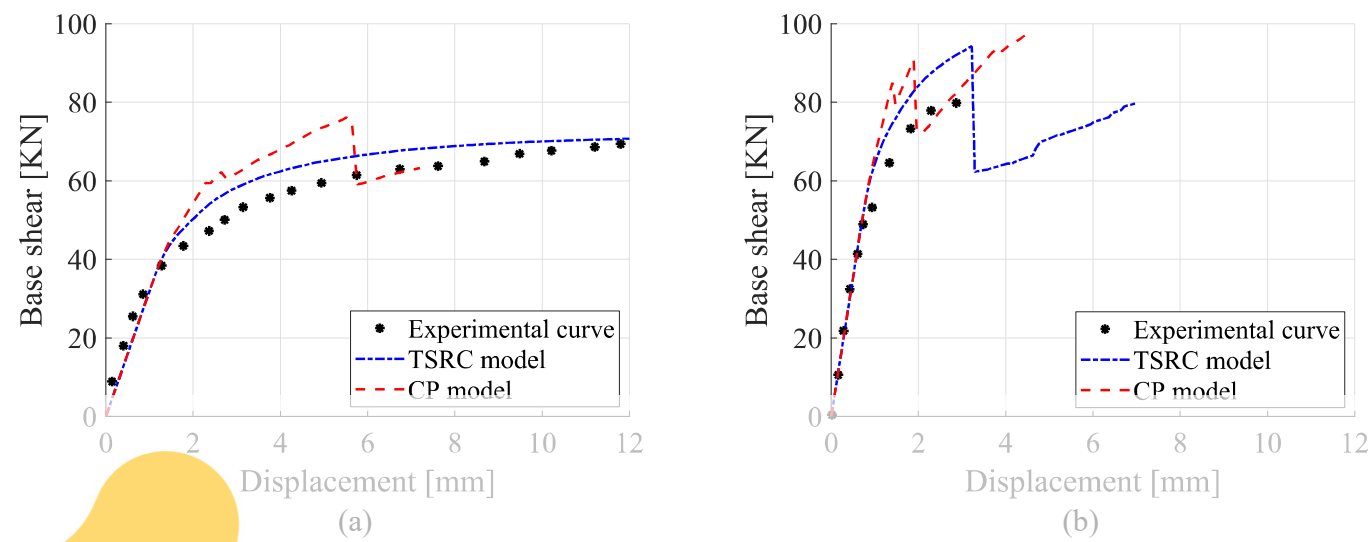

Figure 4: Comparisons between experimental and numerical (TSRC and CP) force-displacement response curve under monotonic loading: (a) high or slender panel, and (b) low or squat panel.
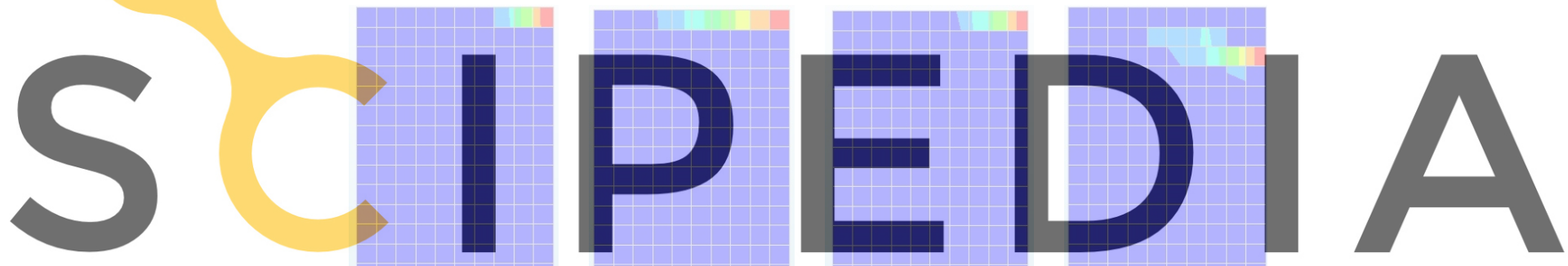

Register for free at https//www.scipedia.com to download the version without the watermark

(a)

(b) (c) (d)

Figure 5: Crack patterns for the high (slender) wall: (a) TSRC for $\mathrm{s}=2 \mathrm{~mm}$; (b) TSRC for $\mathrm{s}=12 \mathrm{~mm}$; (c) CP for $\mathrm{s}=2 \mathrm{~mm}$; and (d) $\mathrm{CP}$ for $\mathrm{s}=6 \mathrm{~mm}$.

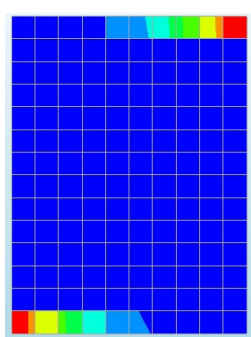

(a)

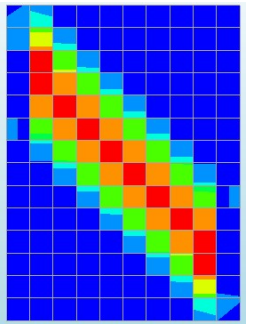

(b)

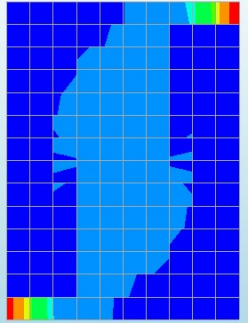

(c)

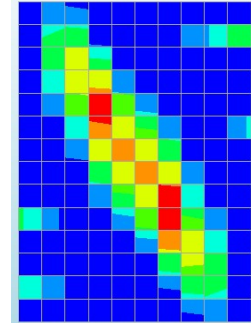

(d)

Figure 6: Crack patterns for the low (squat) wall: a) TSRC for $\mathrm{s}=2 \mathrm{~mm}, \mathrm{~b}$ ) TSRC for $\mathrm{s}=7 \mathrm{~mm}, \mathrm{c}$ ) $\mathrm{CP}$ for $\mathrm{s}=2$ $\mathrm{mm}$, d) $\mathrm{CP}$ for $\mathrm{s}=4 \mathrm{~mm}$. 


\subsection{Cyclic loading}

Regarding the cyclic tests performed within the selected experimental campaign (see Figure 3 ), the cyclic displacement-history shown in Figure 7 is applied to the two panels. The results obtained with the two FE models, the TSRC (blue dashed-point curves) and CP (red dashed curves) models, are presented in Figures 8 and Figure 9 and compared with the experimental outcomes (black star symbols) for high and low panels in terms of force-displacement global curve.
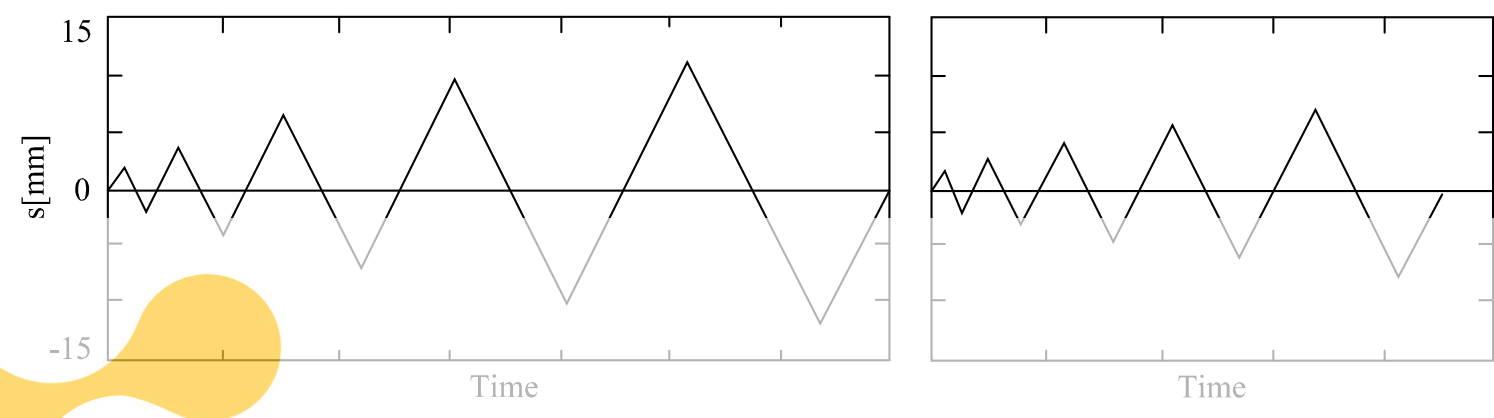

(a)

(b)

Figure 7: Cyclic displacement history applied to high (a) and low (b) panel.
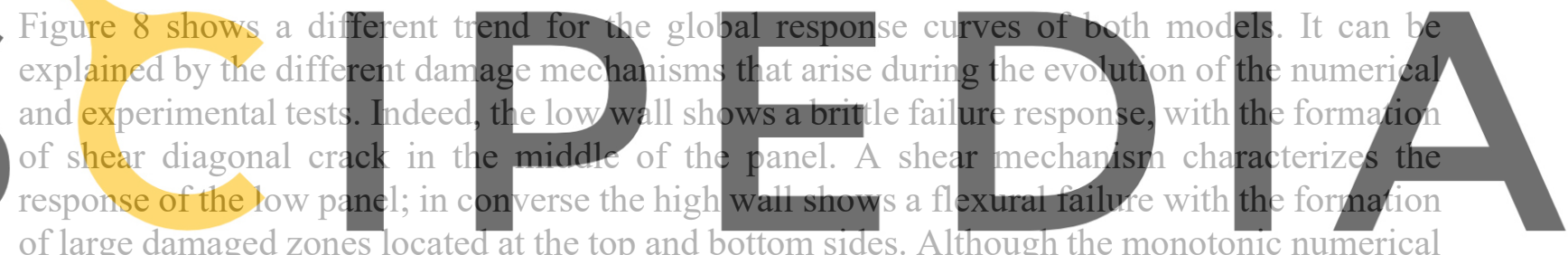

of large damaged zones located at the top and bottom sides. Although the monotonic numerical analyses seem to reproduce well the damage mechanisms occurring in the two panels (Figure 5

satisfactory. In particular, the numerical models are unable to describe the hysteretic dissipation mechanisms, which is the area under the experimental cyclic curves, particularly relevant for the nonlinear response of the low panel.

To overcome the latter limitation of both models to match the experimental response, the modified version of the CP formulation, i.e. the MCP model, has been adopted as introduced in section 2.1. Figure 10 shows the comparison between the results obtained with the MCP model (magenta dashed curves) and the experimental outcomes (black star symbols) for both the panels. The numerical results obtained for the high panel correlates now better with the experimental response. Yet, the advantage of using the MCP model is less evident in the case of low panel. To be noted is that, in this model, the plasticity evolution is controlled by the cohesion that is, by itself, ruled by the compressive strength. Therefore, starting from an experimental compressive strength value, the effect of plasticity is not properly taken into account during the dissipation process. Instead, starting from an experimental cohesion value, numerical results are more consistent with the experimental ones, although the compressive strength threshold seems to be unrealistic. This issue deserves further investigations. 


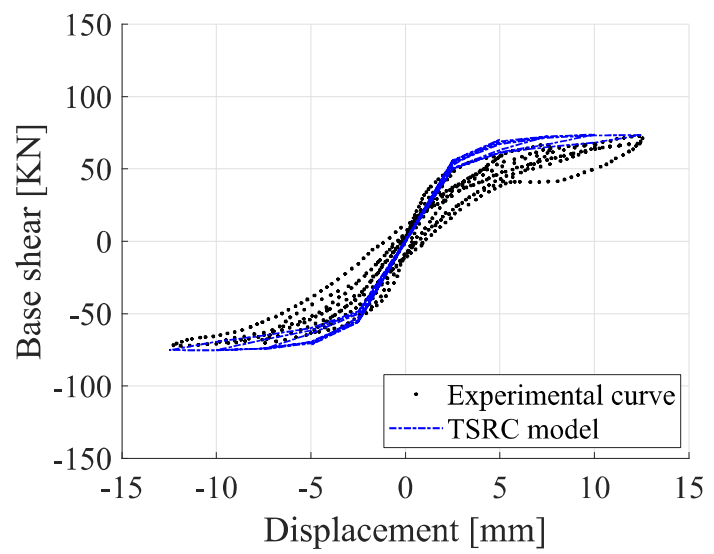

(a)

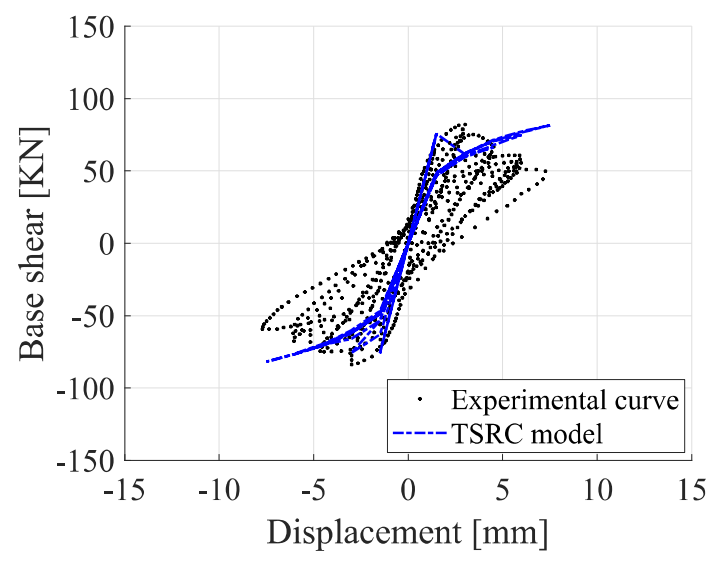

(b)

Figure 8: Comparisons between experimental and numerical (TSRC) force-displacement response curve under cyclic loading: a) high and b) low panel.

Furthermore, a comparison with the macromechanical continuum damage-plastic model presented in [13] is performed (Figure 11). The mechanical parameters used for this model are also deduced from [13]. The damage-plastic model reproduces better the experimental responses, especially for the low wall. Indeed, this satisfactorily describes the effect of the energy dissipation due to shear mechanisms occurring in the panel. Regarding the crack patterns (Figure 13), both the latter models are able to describe the distinctive features of flexural and shear response shown by the high and ow masonry panels during the experimental campaign although the continuum damage-plastic model gives more spread damaged in respect to the MCP. This is due to the different way that bath models describe the masonry, that is by neans of the introduction of a continuum damage variable or adopting a smeared crack formulation, as well as to the different regularization technique implemented.

Register for free at https//www.scipedia.com to download the version without the watermark

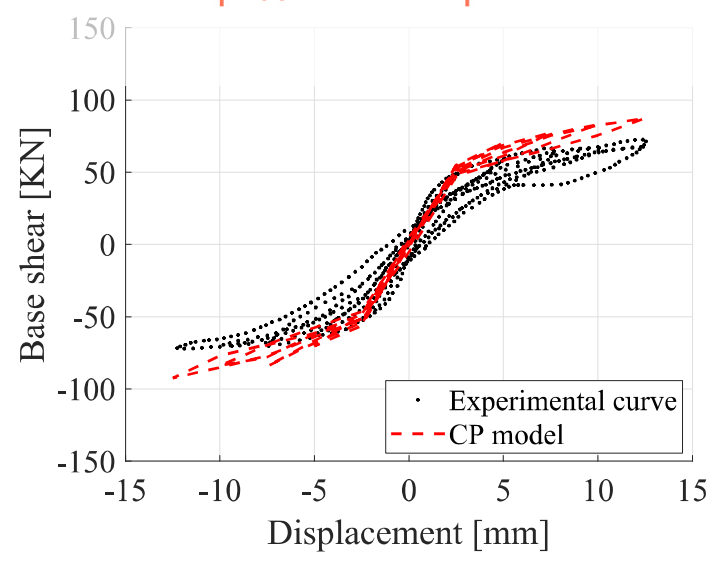

(a)

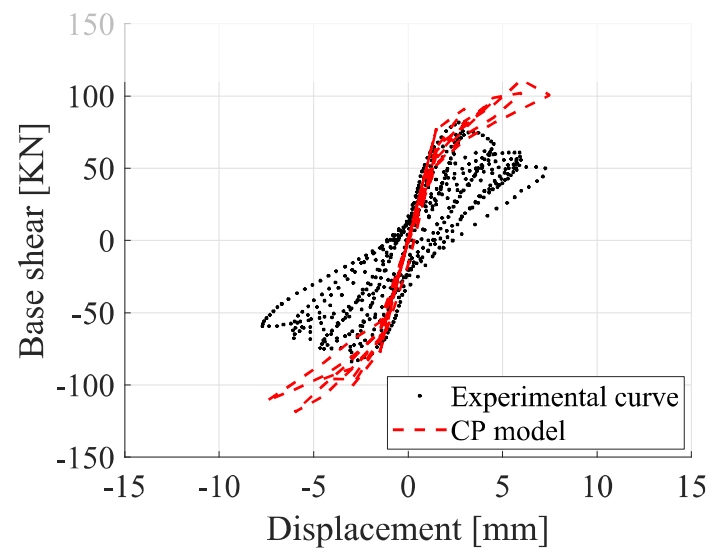

(b)

Figure 9: Comparisons between experimental and numerical (CP) force-displacement response curve under cyclic loading: a) high and b) low panel. 


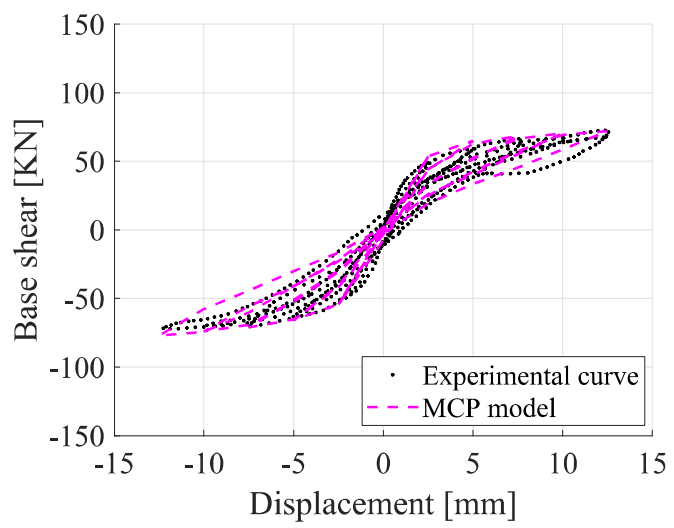

(a)

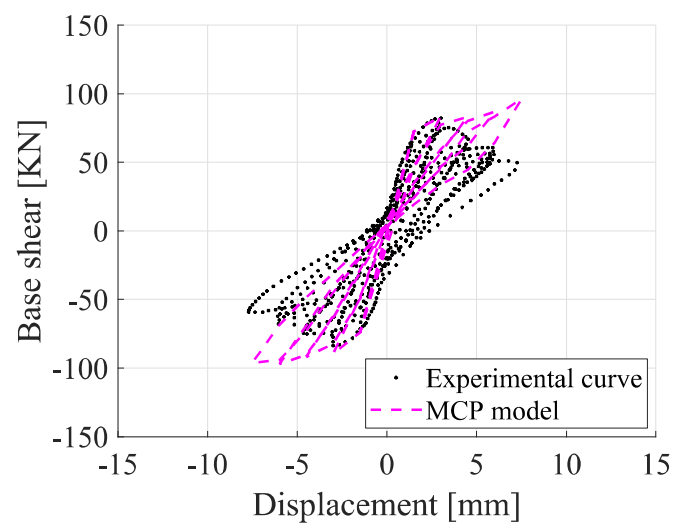

(b)

Figure 10: Comparisons between experimental and numerical (CPM) force-displacement response curve under cyclic loading: a) high and b) low panel.
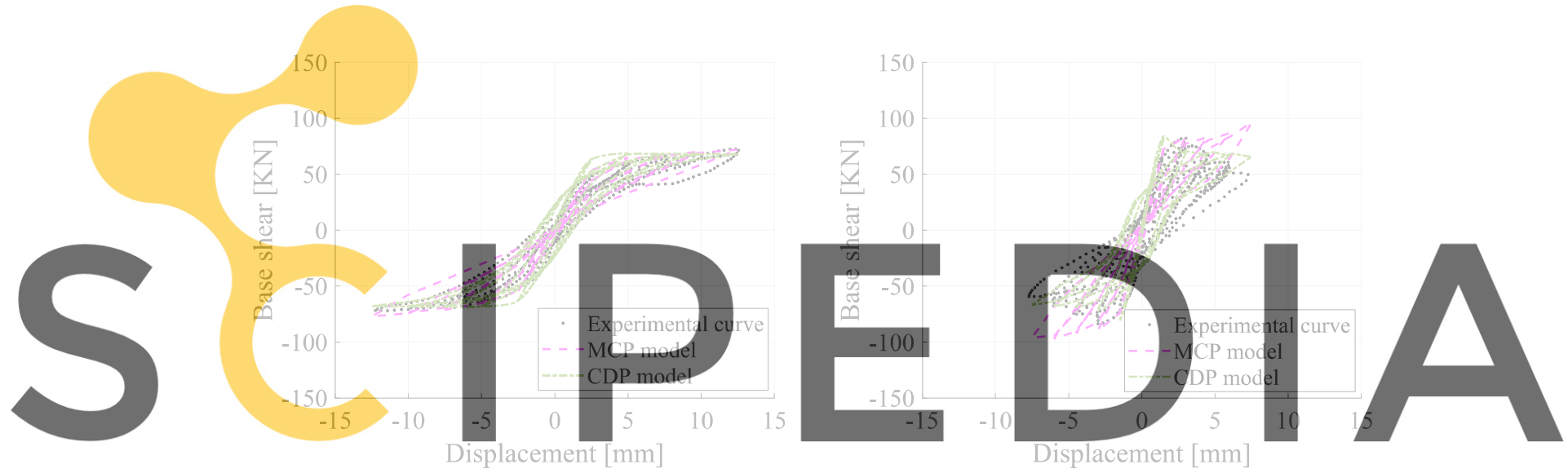

Register for free at https//Www.scipedia.com to download the version without the watermark curve under cyclic loading: a) high and b) low panel.

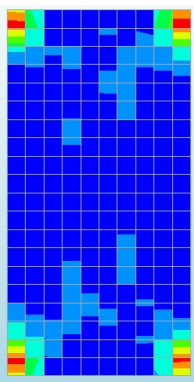

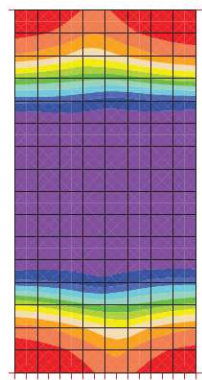

(a)

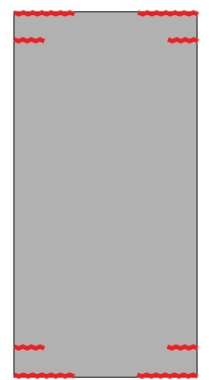

Figure 12: Crack patterns: MCP, CDP and experimental outcomes: a) high and b) low panel.

\section{CONCLUSIONS}

The structural response of two masonry panels (low or squat and high or slender) experimentally tested by Anthoine et. al [18] has been numerically reproduced through different 
macromechanical FE models: (i) based on smeared crack approach; and (ii) based on a continuum damage model. In particular, the use of macro-modelling techniques based on smeared crack and coupled damage-plastic constitutive laws for the cyclic in-plane response prediction of these masonry panels was explored. A fracture energy regularization technique was used for the smeared crack models and a nonlocal integral approach for the continuum damage-plastic model.

Two material constitutive macro-models, known as Total Strain Cracking (TSRC) and Crack and Plasticity (CP), have been used to simulate the response of the two panels. These have different geometries and, therefore, different damage paths. Indeed, a shear mechanism characterized the behavior of the low panel. In converse, a flexural rocking response distinguished the high wall with the formation of large damaged zones located at the top and bottom sides. The numerical models have showed some shortcomings, i.e. although the numerical analyses have showed a good agreement reproducing the damage mechanisms, the comparisons in terms of force-displacement curves were not completely satisfactory. Regarding the TSRC model, the numerical results were consistent with the model formulation built just with a cracking constitutive law. Conversely, although the CP model is based on a coupled cracking-plastic constitutive law, its formulation presents some limitations when taking into account the effect of plasticity during the dissipation process. The latter issues were somehow solved through a modified version of the Drucker-Prager model (MCP) by including a cohesive softening law in the existing CP model. For the high wall, the numerical results correlate better with the experimental output with respect to the CP and TSRC models. For the low wall, the correlation was still not very satisfactory and other modifications are required.

Lastly, a comparison between the MCP model, categorized as a smeared crack model, and a CDP macromechanical continuum damage-plastic model [13] was performed. This latter sophisticated model, where damage and plasticity are coupled, proved to be more capable to reproduce the experimental outcomes in terms of force-displacement global curve. Hence, other experimental campaigns on masonry panels and/or larger structures, may be considered to further validate the capabilities of the numerical models to reproduce the masonry response under cyclic-loading conditions and to better understand its advantages and limitations. Furthermore, the analyzed constitutive models can be enriched, in particular the CP formulation, through rigorous mechanically based modifications inspired by continuum damage-plastic models.

\section{REFERENCES}

[1] G. Brandonisio, G. Lucibello, E. Mele, and A. De Luca, "Damage and performance evaluation of masonry churches in the 2009 L'Aquila earthquake," Eng. Fail. Anal., vol. 34, pp. 693-714, 2013.

[2] P. B. Lourenço, N. Mendes, L. F. Ramos, and D. V. Oliveira, "Analysis of Masonry Structures Without Box Behavior," Int. J. Archit. Herit., vol. 5, no. 4-5, pp. 369-382, Jul. 2011.

[3] E. Sacco, D. Addessi, and K. Sab, "New trends in mechanics of masonry," Meccanica, vol. 53, no. 7, pp. 1565-1569, 2018.

[4] P. Roca, M. Cervera, G. Gariup, and L. Pela', "Structural Analysis of Masonry Historical Constructions. Classical and Advanced Approaches," Arch. Comput. Methods Eng., vol. 
17, no. 3, pp. 299-325, Jul. 2010.

[5] D. Addessi and E. Sacco, "Nonlinear analysis of masonry panels using a kinematic enriched plane state formulation," Int. J. Solids Struct., vol. 90, pp. 194-214, 2016.

[6] P. B. Lourenço and J. G. Rots, "Multisurface Interface Model for Analysis of Masonry Structures," J. Eng. Mech., vol. 123, no. 7, pp. 660-668, Jul. 1997.

[7] L. C. Silva, P. B. Lourenço, and G. Milani, "Derivation of the out-of-plane behaviour of masonry through homogenization strategies: micro-scale level," Comput. Struct., vol. 209, pp. 30-43, 2018.

[8] L. Karapitta, H. Mouzakis, and P. Carydis, "Explicit finite-element analysis for the inplane cyclic behavior of unreinforced masonry structures," Earthq. Eng. Struct. Dyn., vol. 40, no. 2, pp. 175-193, 2011.

[9] D. Addessi, "A 2D Cosserat finite element based on a damage-plastic model for brittle materials," Comput. Struct., vol. 135, pp. 20-31, 2014.

[10] L. Pelà, M. Cervera, and P. Roca, "An orthotropic damage model for the analysis of masonry structures,” Constr. Build. Mater., vol. 41, pp. 957-967, Apr. 2013.

[11] L. C. Silva, P. B. Lourenço, and G. Milani, "A discrete macro-model using homogenization with strain-rate dependency for the out-of-plane study of masonry panels subjected to impact loading," in ECCOMAS Thematic Conference on Computational Methods in Structural Dynamics and Earthquake Engineering, 2017.

[12] L. C. Silva, N. Mendes, P. B. Lourenço, and J. Ingham, "Seismic Structural Assessment of the Christchurch Catholic Basilica, New Zealand," Structures, vol. 15, pp. 115-130, 2018.

[13] C. Gatta, D. Addessi, and F. Vestroni, "Static and dynamic nonlinear response of masonry walls," Int. J. Solids Struct., vol. 155, pp. 291-303, 2018.

[14] L. Kachanov, "Rupture time under creep conditions," Izv. Akad. Nauk SSSR, vol. 8, pp. 26-31, 1958.

[15] J. G. Rots, "Computational modeling of concrete fracture," 1988.

[16] R. De Borst and P. Nauta, "Non-orthogonal cracks in a smeared finite element model," Eng. Comput., vol. 2, no. 1, pp. 35-46, 1985.

[17] J. G. Rots and J. Blaauwendraad, "Crack models for concrete: discrete or smeared? Fixed multi-directional or rotatin?," Heron, vol. 34, no. 1, pp. 3-59, 1989.

[18] A. Anthoine, G. Magonette, and G. Magenes, "Shear-compression testing and analysis of brick masonry walls," in Proceedings of the 10th European conference on earthquake engineering, 1995, vol. 3, pp. 1657-1662.

[19] DIANA, 2019, DIsplacement ANAlyzer finite element software package, version 10, DIANA FEA, Delft, https://dianafea.com. .

[20] C. Comi and U. Perego, "Fracture energy based bi-dissipative damage model for concrete," Int. J. Solids Struct., vol. 38, no. 36-37, pp. 6427-6454, 2001.

[21] G. Pijaudier-Cabot and Z. P. Bažant, "Nonlocal damage theory," J. Eng. Mech., vol. 113, no. 10 , pp. $1512-1533,1987$.

[22] G. Magenes and G. M. Calvi, "In-plane seismic response of brick masonry walls," Earthq. Eng. Struct. Dyn., vol. 26, no. 11, pp. 1091-1112, Nov. 1997.

[23] P. B. Lourenço, "Recent advances in masonry modelling: micromodelling and homogenisation," in Multiscale modeling in solid mechanics: computational approaches, World Scientific, 2010, pp. 251-294. 